\title{
Como Se Morde um Pai? Estudo de Caso de um Jovem Autista: Uma Abordagem Psicanalítica
}

\author{
Maria Elisabeth Araújo" ${ }^{* a}$ \& Carlos Alberto Ribeiro Costa ${ }^{b}$ \\ ${ }^{a}$ Universidade Federal Fluminense, Rio de Janeiro, Brasil \& ${ }^{\mathrm{b}}$ Universidade Federal do Rio de Janeiro, Rio de Janeiro, Brasil
}

\begin{abstract}
RESUMO
Através da abordagem de episódios de "passagem ao ato", em que um paciente autista morde o pai, este trabalho debate as vicissitudes ocasionadas pela ausência do nome do pai como mediador das relações do sujeito com a alteridade, a dimensão objetal e a imagem. A discussão sobre o lugar que as "mordidas no pai" tiveram na economia libidinal deste sujeito aborda questões referentes à autoridade, a não diferenciação sexual e a construção da imagem de si. O trabalho tece considerações a propósito do apaziguamento possível de se acessar através da invenção de um corpo em suas relações com os registros Real, Simbólico e Imaginário, tal como concebido por Jacques Lacan.
\end{abstract}

Palavras-chave: autismo; passagem ao ato; nome do pai; holófrase; corpo.

\section{ABSTRACT \\ How to Bite a Father? Case Study of an Autistic Youngster: A Psychoanalytical Approach}

Through the approach of episodes of "passage to the act" in which an autistic patient bites the father, this paper discusses the events occasioned by the absence of the name of the father as a mediator of relations between the subject and the otherness, the object-dimension and the image. The discussion about the place that "bites the father" had in the libidinal economy of this subject deals with issues relating to authority, sexual non-differentiation and the building of self-image. The study discusses the appeasement possible to access through the invention of a body in its relations to the Real, Symbolic and Imaginary registers, as exposed by Jacques Lacan.

Keywords: autism; passage to the act; name of the father; holophrasis; body.

André tem dezessete anos, e desde os nove encontra-se em tratamento semanal. Embora raramente enderece palavra ao semelhante, o que é compatível ${ }^{1}$ com o diagnóstico de autismo, pode-se dizer que, atualmente, André interage socialmente de maneira satisfatória. A mãe e a avó lideram um centro de candomblé com cerca de 50 associados. André gosta de frequentá-lo e já dispunha de boa acolhida ali, mesmo quando apresentava crises de intensa agitação, mediante algo que tivesse, para ele, efeito invasivo. Essas crises de difícil contenção, tão frequentes quando André era mais jovem, tornaram-se eventuais. Recentemente, no entanto, ele apresentou dois episódios de agressividade física contra o pai. No primeiro, o mais violento, atacou-o com mordidas e chutes. $\mathrm{O}$ segundo, bem mais brando, aconteceu cerca de dois meses depois. Levando em conta a singularidade desses acon- tecimentos, a questão deste trabalho é interrogar a propósito do lugar desses episódios na história de André.

A agitação e a agressividade eram preponderantes no comportamento de André, desde tenra idade. Consideramos que tenham amenizado, ao longo desses anos de trabalho, principalmente, devido a dois fatores: por um lado, atribuímos essa mudança à ampliação horizontal de elementos significantes, de tal forma que, hoje, as reações de agressão e autoagressão, que aconteciam no tempo em que a pulsão servia-se apenas do corpo como forma de escoamento, podem deslizar para as verbalizações. Isto permite supor tratarse, aqui, de um trabalho sobre a holófrase: André produz sinais diferentes uns dos outros, mesmo que não chegue a organizá-los numa sequência lógica, vale dizer, articulada. Ele cria estas sucessões por não ser

* Endereço para correspondência: Maria Elisabeth Araújo: m.elizabeth.araujo@terra.com.br 
capaz de formar séries significantes que o representem na linguagem. Diante de situações que o angustiam, atualmente, ele é capaz, por exemplo, de tranquilizarse ao andar de um lado para outro, repetindo, sem parar, certas sequências de palavras, como "Barteritaaaa! Barterita não é uma batedeira Walita!" ou "Não chora, não. Já passou.".

Ainda que, às vezes, chore, expressando francamente sua dor, suas palavras parecem enxertadas, desvinculadas do afeto e de qualquer apelo, como expressões recortadas do Outro real e sobrepostas ao corpo inconstituído, num emaranhado de significantes puros, isto é, que não significam nada. A essas "falações"2, podem estar associados rituais, como cuspir em uma das mãos ou dar tapinhas na barriga. Em outras situações, pode dar um chute de leve no seu suposto agressor, dizendo com voz cantada e caricata: "Não pode bater".

Estas palavras ou estes "chutes" não parecem indicar que ele tenha sido afetado pela metáfora, que atrela o significante não apenas à função de representar o sujeito, mas de fazê-lo para outro significante, o que estabelece uma relação de alienação e de separação entre significante e sujeito. No caso de André, a metáfora permanece ex-sistente a suas palavras, que persistem como palavras sem alteridade. Assim, pode-se dizer que o apaziguamento de suas relações com o entorno social se deve à ampliação de recursos imaginariossimbólicos, o que é muito diferente de uma apropriação simbólica.

\section{A mãe}

O apaziguamento das reações paroxísticas que André apresentava, mediante certas intervenções provenientes do Outro, deve também ser atribuído ao exaustivo trabalho ao qual a mãe se dedicava, no sentido de pacificar por ele esta iniciativa. Ela estava sempre atenta, no sentido de preveni-lo, com a antecedência que lhe era possível, sobre acontecimentos que escapavam a sua rotina. Afligia-se ao pensar que, um dia, o filho "ficaria alto como o pai" e temia que ele, então, se tornasse indomável. Assim, vivia constantemente em alerta, a fim de perceber o menor sinal de irritabilidade e agir precocemente, "antes que a situação fique fora de controle". Ao detectar os primeiros indícios de desconforto, a mãe de André intervinha, de modo carinhoso e eficaz. No entanto, desta forma, ela também se instalava num lugar de escravidão, com relação a André. De fato, esse aprisionamento tinha sua face de gozo controlador, que não se exerce apenas sobre ele. Ela tomava conta de tudo com muita dedicação, exercitando, nessa atividade permanente de cuidar de todos, o afastamento de seu "medo da morte".

Quando, em sua análise, foi capaz de dizer algo desse medo, Daniela, a mãe de André, pôde enfim abandonar parte dos cuidados com a casa e com o centro e autorizar-se à atividade profissional de artesã. $\mathrm{Na}$ medida em que progride nesse trabalho, ela deixa de ocupar-se obsessivamente de todos. Isso faz emergir uma situação de tensão na relação com André e evidencia em Daniela uma irritabilidade anteriormente contida. Ela passa a queixar-se de dificuldades para lidar com o filho; mostra-se cansada de suas exigências e repetições. Ele, coincidentemente, chora o dia inteiro, pedindo pelo pai. Ela, agora, se aborrece, cumprindo as exigências de seus rituais e dizendo a ele, a todo o momento, que o pai "ainda vai demorar, só chega à noite".

A mãe pôde reconhecer, nessa queixa, que não chega a ser um apelo ao pai, o esvaziamento de sua onipotência. A despeito da indiscutível monotonia implicada numa situação como essa, talvez o mais aborrecido para Daniela seja ceder o devido lugar ao pai e, consequentemente, à morte. Ela intervém menos na relação entre o pai e André, mas é no filho mais velho que deposita maior confiança quanto ao saber lidar com André. "Ele tem mais jeito pra falar, o pai quer fazê-lo entender as coisas na marra".

Nessa ocasião, André permanece pouquíssimo tempo nas sessões e, em sua fala, destacam-se frases em tom choroso: "Assim quebra o espelho! Papaaai! Para de bater na Juliana! Garaviita! Ããããa! Rrãããa!!”.

Os cuidados obsessivos da mãe cedem lugar ao investimento desejante desta, que se atualiza, seja no trabalho em análise, seja no ofício de artesã. Tal mudança acarreta uma ausência que, impedida de convocar uma resposta metafórica, provoca em André, não o grito de apelo, que marca o vazio que inaugura a série significante, mas uma convocação ao pai que se expressa num lamento fraco e ineficaz, como marca simbólica, não ultrapassando o registro do imaginário. Esse choro e essa chamada ao pai parecem abordar a impossibilidade real, através de uma tentativa de traduzir a falta no registro imaginário, já que o simbólico não comparece com sua consistência de buraco (Lacan, 1974/1975). Neste momento, a analista coloca um quadro na sala, onde passa a escrever frases que ele pronuncia.

Há algum tempo, André já evidenciara, nos atendimentos, preferência pelas figuras femininas das revistas. Nessa ocasião, ele volta a interessar-se prioritariamente por elas, mas, agora, não para olhá-las e 
acariciá-las, mas para recortá-las e, principalmente, cortá-las em pedaços: boca, orelhas, olhos. Ocupandose deste trabalho, que concerne à construção de bordas, numa relação com um Outro menos avassalador, André suporta novamente permanecer na sala por mais tempo.

\section{A mordida no pai}

O reconhecimento de si mesma, como profissional, requereu, de Daniela, anos de trabalho em análise e não prescindiu de um documento que o comprovasse: o registro no conselho de artesãos. O progresso em sua atividade acarretou, de Daniela, uma viagem à Salvador, onde apresentaria sua grife, inspirada em motivos do candomblé. Seria a primeira vez, em 16 anos, que ela deixaria André por dez dias.

Durante a ausência da mãe, a família não conseguiu organizar-se para levar André às sessões e, consequentemente, ele faltou a dois atendimentos. Só quando voltaram, a analista soube que uma semana após a partida da mãe - numa tarde de domingo, todos em casa, o pai e os três filhos no andar de baixo, os avós maternos na casa deles, no andar de cima - aconteceu o inusitado! Como de hábito, o pai, que chamaremos de Walter, via tv, quando André faz mais um de seus comentários a propósito do papagaio do vizinho, "Fala pro papagaio calar a boca!", atento em seu programa, indiferente, o pai dá a resposta corriqueira, que se suporia esperada: "Não pode ir na casa do vizinho". Inesperadamente, André investe contra o pai, mordendo-o com ferocidade, a ponto de machucálo bastante. Walter se deixa morder, numa passividade surpreendente, e pede ajuda ao filho mais velho, que consegue fazer André largar o pai e leva-o para o quarto do casal, onde se tranca com ele, medica-o e lhe faz companhia, até que se acalme. Mediante a fragilidade do pai, contando com o aval da mãe e, de certa forma, ocupando o seu lugar, é o filho mais velho que tem alguma ascendência sobre André.

Vemos a ausência inédita da mãe coincidir com a voracidade sem precedentes com que André investe contra o corpo de Walter. Ao morder e chutar o pai, estaria o filho atribuindo a ele seu devido lugar como responsável pelo desaparecimento da mãe? A função paterna indica que o desejo da mãe remete a algo para além do filho. Não operando esta função, a indiferença evidenciada no "não" de Walter oferece a André uma falta de lugar. À medida que falta a "falta" inerente ao campo do desejo, a angústia se presentifica de forma avassaladora, precipitando a passagem ao ato. Quando o pai papagaia, o problemático não é que o pai não dispense atenção ao filho, mas sim que, ao "papagaiar", isso é recebido, por André, como oferta de lugar nenhum. De qualquer forma, é possível supor que essa passagem ao ato indique a tentativa de incorporação real do pai, mediante a ineficácia de sua incorporação no simbólico.

No retorno aos atendimentos, ele anda pela sala, cuspindo na mão e dizendo em tom repreensivo: "Não deve fazer isso!", dando ênfase ao "não" da frase. Desconhecendo ainda o ocorrido, a analista supôs que André referia-se ao fato da mãe ter viajado, o que não seria muito coerente, pois indicaria uma frase enunciada para a mãe. O pai solicitou uma entrevista para mostrar-me o flagelo em que se transformara. Foi espantoso não apenas vê-lo cheio de hematomas pelo corpo, mas a passividade com que aceitara a agressão. A convicção que tinha de que defender-se tornaria o filho mais violento não abria espaço para a interrogação a propósito do gozo de Walter implicado nisso.

\section{A construção de séries}

Nas sessões, André se expressa através da repetição de frases e de rituais que, lentamente, vai produzindo, modificando e articulando. Elas têm a nítida função de apaziguamento e parecem indicar um trabalho capaz de promover algum tipo de estabilização. Pode-se supor que, através dessas séries, o autista se protege da falta introduzida pela iniciativa do Outro, ao mesmo tempo em que expressa sua subjetividade inconstituída. É a partir desta falta que ele se oferece à intervenção do analista, que deve, num primeiro momento, inserir-se nela.

A amarração borromeana entre Real, Simbólico e Imaginário ampara o sujeito que, a seu modo, com seu sintoma, faz laço social, estabelecendo um quarto elo, que o nomeia e orienta seu discurso. Quando o enodamento borromeano não ocorre, o sujeito permanece à deriva, como resto discursivo do Outro. Tal como qualquer falante, o autista recolhe do dia a dia as frases que constituem seu dito. Diferencia-se, no entanto, na medida em que esse dito se caracteriza por expressar uma relação entre Simbólico e Real, onde não se estabelece a operação de corte, que, ao presentificar o Real como impossível (ou como ex-sistência), possibilita que o Simbólico assuma sua consistência de buraco ocupável, ainda que parcialmente, pelo sentido em que o Imaginário consiste.

As sucessões que André produz exemplificam a relação tangencial e não borromeana entre Simbólico e Real, o que vem evidenciar que, para que a língua possa se estabelecer como sistema, é preciso que an- 
tes, numa anterioridade lógica, se instale como ato de fala, para dar conta de um sentido que falta. É esse ato que deflagra o engendramento de uma sintaxe, que serve de teia, de rede, de suporte para o sujeito. Embora isso não ocorra nas frases que André verbaliza, na medida em que se reconhece que há uma escolha implicada nessas sequências, é preciso supor que ali comparece um sujeito que, ainda que não ex-sista a elas, existe colado a estas repetições de frases, como numa holófrase (Lacan, 1964/1985). Considerando que estas sequências têm função de apaziguamento e estabilização, interrogamos se elas proporcionariam alguma forma de amarração. Em outras palavras, seria possível representar essas sucessões topologicamente, através de algum tipo de nó, ainda que se trate de um provável falso nó? Ou seriam estas sequências efeito de uma mera acomodação dos três registros, onde, embora eles não se amarrem, se tocam, o que permite algum nível de estabilização?

Fundamentados nas colocações de Freud, na carta 52, podemos afirmar que, para que uma marca tenha valor de inscrição inconsciente, é preciso que a repetição a coloque em oposição a todas as outras (Freud, 1896/1977). Isso equivale a dizer que toda inscrição é marca de uma diferença, o que vai não só conferir singularidade a essa marca, mas estabelecê-la como significante propriamente dito. Chamamos de significante propriamente dito aquele que, ainda que não signifique nada, na medida em que remete a outro significante, na qualidade de representante do sujeito, produz uma significação. As séries que André produz parecem expressar uma etapa anterior à repetição que funda o inconsciente, uma etapa mítica da constituição subjetiva, quando os significantes ainda se apresentariam indiferenciados, numa relação de simultaneidade entre si.

A maneira como André articula as palavras mostra que é possível recolher os significantes do Outro na sua forma direta, sugerindo a falta do passo que garante o lugar vazio do sujeito - o que não implica sua não alienação no Outro. Tal como a presença de uma semitorção numa fita euclidiana altera suas propriedades topológicas, transformando radicalmente sua estrutura, o dito autista evidencia a diversidade de seu funcionamento psíquico, com relação às demais estruturas. A expressão discursiva de André explicita uma subjetividade que não pode comparecer no efeito de remetimento significante, supostamente por não ter sofrido a operação inaugural, que instaura a relação entre sujeito e significante. Lacan expressa esta relação no matema: $\mathrm{S} 1 \rightarrow \mathrm{S} 2$.
Desta forma, tais sucessões que André produz podem ser consideradas S1 sem sentido, que ocupa o lugar de exclusão bem sucedida da falta. Uma vez que não é possível ao Real operar o corte que estabelece o Simbólico, como aquele que lhe faz borda ${ }^{3}$, o trabalho de produção de ciclos é a resposta significante possível para o estabelecimento de uma barreira ao Real. O que quer que compareça como falta, o que corresponderia a uma invasão do Real, fica assim excluído. $\mathrm{Na}$ proposta terapêutica da psicanálise, a observação da escolha destes ciclos coloca o analista na posição de parceiro, viabilizando um enlace que faça borda ao sem sentido e possibilite que essa sucessão assuma o estatuto de um dizer ou de uma rede, onde o sujeito, ainda que não esteja alienado no sentido rigoroso desse termo, se ampare e alcance alguma estabilização.

\section{A evolução}

A ausência da mãe, que ocorre no momento em que ela se lança no trabalho profissional, leva André a reclamar a falta do pai e, a seu modo, talvez convocálo. É o que fica comprovado, inicialmente, em suas lamúrias diárias, pedindo o pai. Nessa ocasião, compareciam, nas sessões, frases imperativas e com certo teor agressivo, tais como: "Mateus, por que você puxou o cabelo do João Paulo? Não estou achando graça nisso! João Walter, não pode fazer bobagem! Larga o João Antônio! Não pode fazer manha!'”. A coincidência entre o aparecimento dessas frases e o pedido repetitivo da presença do pai induz à indagação sobre a possível relação entre as frases imperativas e o apelo ao pai.

O pai, enquanto função simbólica, comparece de forma débil no discurso do casal parental e como impossibilidade para André. A maior potência, atribuída por Daniela ao filho mais velho, no que diz respeito à contenção de André, reforça o enfraquecimento simbólico do pai. Walter, por sua vez, mostra não se crer à altura dessa função, ao alimentar um lugar infantil na relação com a esposa e, consequentemente, com os filhos, endossada por uma permanente fragilidade financeira. No entanto, é de se supor que a precariedade na transmissão da função paterna apenas teve efeito tão devastador na medida em que André encontrava-se concernido em seu não funcionamento.

Após a agressão ao pai, André passou a apresentarse irritado e, com isso, mais exigente quanto aos rituais com a mãe. Nas sessões, apazigua sua agitação com a produção de diversos ciclos, que articulam imagens, números e letras. Assim, escreve nomes e números dos canais de TV, desenha e coloca nomes em séries 
de frutas, de animais, dos signos do zodíaco. Essa produção é permeada pela repetição de frases que são escritas no quadro: "André chutou a tia Clara! Não pode bater no Walter! Não pode tirar o elástico da Giovana; é feio! Saco! Para de fazer bobagem comigo!" Essas três últimas frases, além de expressar agressividade, parecem também fazer menção à diferença entre os gêneros. Paralelamente, persiste na atitude de rasgar figuras femininas. Em algumas sessões, chega a pedir que eu o ajude a manter as figuras inteiras, mas ele mesmo não resiste ao ímpeto de rasgá-las.

Num certo dia, em que chega, dizendo "Não pode bater no Walter", desenha: "tia Ju brava com Walter Josê", "Walter fez bobagem com Álvaro", "tia Joyce brigou com Antônio", "Andréa brigou com André". Ao final da sessão, Walter pede para marcar uma entrevista com a analista, pois André o havia novamente agredido, por ter sido impedido de jogar a bola na rua. No atendimento, o pai se mostra menos abalado do que na vez anterior, pois acredita que "dessa vez houve um motivo". Julgava que, dessa vez, poderia ter evitado, se tivesse valorizado os sinais de irritabilidade que André vinha dando há dias e tivesse sido mais hábil ao abordá-lo. A despeito de sua resposta inicialmente passiva, Walter retifica sua posição subjetiva, ao considerar que André precisa ser punido pelo que fez e priva-o de ir ao centro de Candomblé.

\section{0 que ocorreu nas sessões seguintes}

$\mathrm{O}$ período de tranquilidade que se seguiu à segunda agressão de André ao pai permite supor que a resposta punitiva, sem deixar de ser acolhedora, possa ter colocado Walter mais afinado, com relação à interdição. É interessante observar que isso só pôde acontecer a partir da constatação de sua própria falta perante o filho, o que ocorre no reconhecimento de sua desatenção aos indícios de que não estava bem. Nas sessões, André repetia: "Solange brigou com toda razão".

$\mathrm{O}$ interesse pelos bonecos com órgãos genitais intensificou-se. André tira as calças da boneca e diz: "Não pode colocar a mão na xoxota da Aline". A analista faz um boneco colocar a mão na xoxota da Aline. Ele se diverte com isso. Tira a calça do homem e diz: "André". Procura o bebê, dentro da barriga da boneca grávida, e ele não estava lá. Pede a ajuda da analista e, quando o encontram, diz: "Andrê". Olha a genitália do boneco e diz: "Papai".

Sem dúvida, André sabe da diferença anatômica entre um homem e uma mulher e interessa-se por isso, conferindo, às mulheres, um lugar especial. Associa, com pertinência, a figura masculina ao pai, diante do qual ele é um bebê, talvez pelo obscuro interesse que representa permanecer atrelado à mãe. No entanto, não se pode dizer que se trate do estabelecimento de uma relação edípica.

As frases repreensivas persistem: "Por que você puxou o cabelo do João Paulo? Não faz isso com a Malu!'. Passa a solicitar que a analista encene com os bonecos o que ele fala, frequentemente retornando à temática agressiva: "A dona Florinda bateu no seu Madruga. O Quico deu um tapa no seu Madruga. A Chiquinha chorou." ${ }^{4}$. Nessa ocasião, André apresenta dificuldades nas despedidas; por exemplo, tem que se despedir de todos os colegas e vê-los ir embora, antes de sair da escola.

Num certo dia, após desenhar suas mãos no quadro, passa a servir-se do livro da "Branca de Neve" em todas as sessões, durante cerca de quatro meses ${ }^{5}$. De início, quer que a analista nomeie todas as figuras do livro. Ela o faz, mas também escreve no quadro as frases que ele lê e dá destaque. Num dado momento, ele passa a apagá-las e a escrever séries de números e letras.

Na sequência, fala do medo: "Tem medo do Louis Armstrong. Tem medo do quadro, do amigo preti$n h o "$. Ao medo, seguem-se frases que dizem respeito ao olhar: "Olha o homem olhando pro ganso! A madrasta olhou no espelho. Olha a mulher! Os homens saíram correndo atrás das mulheres. Olha o homem olhando os três peixes na água! Olha o homem olhando os urubus! Olha o menino escrevendo!".

Algumas sessões depois, ainda servindo-se dos contos dos irmãos Grimm, destaca: "A menina está triste, porque a velha não quer dar a maçã para ela. Uma cereja verde, duas cerejas vermelhas. Um chocolate preto, um chocolate branco. Uma arara azul, uma arara vermelha."

Quando deixa o livro da Branca de Neve, pede uma folha e passa a fazer três desenhos, que são intitulados por ele como: "Tia Ju brigou com Walter Manuel. Tia Joyce brigou com Antônio chorando. Tia Andréa brigou com André chorando." Há cerca de dois meses, André repete esta sequência em todas as sessões.

\section{Observações finais}

Ao que parece, a aposta realizada por Daniela no ofício de artesã impôs um encontro com a impossibilidade: por meio desta, pôs-se em suspenso a espera 
por garantias, rotinas e predições que lhe eram peculiares. $\mathrm{O}$ enfastiamento que emerge para esta mulher, quando conquista a dedicação a seu ofício, evidencia, por um lado, o gozo presente na relação com André, e, por outro, a abertura de uma nova via: o comparecimento do imponderável, implicado em qualquer aposta, no caso, aquela disposta no trabalho. Pode-se supor que a ocupação com a casa e, sobretudo, com André viabilizava o encobrimento da falta vivida, como incerteza com relação a sua competência profissional. Esta incerteza, ao fazer vacilar o investimento outrora voltado para André, cede ao desejo atualizado na relação de Daniela com o trabalho. Surgem, então, as solicitações de André ao pai. Nas sessões, esse lamento na forma de chamado (Papai!) é concomitante a frases como "Assim quebra o espelho", frases estas que indicam que o que está em jogo, neste "chamado", é o risco de uma quebra, oriunda da impossibilidade de acesso ao pai simbólico.

Segundo Soler (2007), o autista se detém na borda da alienação ao significante. Estando às portas deste contar-se no campo da linguagem, o autista trabalha, também, na construção das bordas que serão, assintoticamente ou não, as de seu corpo próprio. É o que se evidencia no ofício ao qual André se dedica, recortando, nas imagens de mulheres, bocas, olhos e ouvidos. Este "cortar" figuras de mulheres presentificaria, assim, um tratamento do Outro real - e da impossibilidade avassaladora do feminino - assim como inaugura uma via de acesso à imagem corporal: é desde este trabalho que se torna possível a cena que André pode se olhar: "Olha o menino escrevendo".

Nesta relação com a alienação a constituir, Lacan considera que os autistas são, sobretudo, verbosos (Lacan, 1975/1998). Maleval (2007) entende este gozo do verbo como insígnia da falta da extração do objeto vocal, que apresenta o real não cifrado como impossível. As frases de André, neste momento, parecem confirmar a direção da escuta, pois, a despeito do não comparecimento do simbólico, marcando a impossibilidade, a verbosidade presentificada neste "lamento" parece indicar o lugar marginal de André, com relação à fala.

Considerando que o pai tem como um de seus efeitos a função simbólica de interdição, não é de estranhar que o interesse pela diferença entre os sexos tenha se intensificado, a partir da atitude punitiva assumida por Walter. No entanto, a diferença entre os gêneros, tal como posta em cena por André, não vai além da alternância, do jogo de oposições, o que equivale a dizer que não vai além da bifididade do significante.
Diante do impedimento do corte que a metáfora representa, as frases repreensivas indicam: 1) o trabalho permanente de defesa à invasão do Outro; 2) a sustentação do que é viável, para André, do pai como nome (Lacan, 1974/1975). A encenação, concomitante ao trabalho de corte, é uma variante do mesmo trabalho, dando esteio para a construção do duplo imaginário. Por outro lado, a imagem, a posteriori, assim como a encenação, permite ao paciente um tratamento do pavor, por ele evocado: enquadra-se seu medo dirigido a certos quadros, como o cartaz do filme Amadeus, o quadro do "menino pretinho", pintado pela mãe, e o de Charles Chaplin. O recurso à imagem permite, ainda, outro modo de acesso a algo que o fascina: o quadro da estátua, da mulher lendo um livro, das meninas de Velásquez.

Mas como pensar a coadunação deste trabalho de André com o episódio que o deflagrou? Como vimos, o episódio dramático da primeira mordida do pai se inicia, curiosamente, com o dito: "Fala para o papagaio calar a boca". André estava, mais uma vez, incomodado com o ruído agudo com o qual o papagaio do vizinho corriqueiramente o transtornava.

No entanto, não deixa de ser inusitado que, de seu incômodo, emirja esta frase imperativa que no "só depois" parece remeter a "fazer calar": 1) a fala papagaiada de André - que passa a construir novos ciclos (além das bordas corporais); e, 2) o papagaiar de Walter que, ainda que momentaneamente, se reconheceu concernido, em sua relação com André. Se for impossível ter certeza disto, fato é que esta frase antecedeu, mediante o encontro com a fala uma vez mais papagaiada do pai, a passagem ao ato. A direção da cura, entretanto, não se resume a isto; trata-se, antes, de sustentar a transmutação daquela "passagem ao ato" em "ato".

A escuta psicanalítica viabilizou, em condições propícias, a elevação dessa passagem ao ato 'à dignidade de um ato'. Um ato que, nos limites do saber, inscreve uma subtração no real, um sulco, e não a diferença sexual. É desde esta inscrição, no corpo de Walter, que André passaria a buscar o apaziguamento na proliferante repetição de frases de tom agressivo e imperativo. Estas frases que são enlaçadas pela analista, através da escrita no quadro. André se apóia nelas para produzir ciclos que vinculam imagens, números e letras: nomes e números de canais de TV, desenhos, nomes e cores de frutas, animais, signos do zodíaco. Uma vez que o pai simbólico, como marca da dessimetria e de uma autoridade consentida, encontra-se ausente, mister se faz construir novos modos de relação com a dimensão da autoridade. 
Quando o corpo esfacelado de André comparece em subtrações nas figuras femininas cortadas, talvez algo deste esfacelamento incida sobre o corpo de Walter, marcado pela mordida que o descompleta. Tal manobra permitira a André incluir uma diferença no real. Reagrupando os sinais, André pode se incluir na série onde se contam três meninos que "fazem bobagens" e que, por causa destas, são repreendidos: "Walter José (nome do pai), Antônio e André". Mordido pelo real presentificado por André, Walter, ante o segundo ataque, julga-se capaz de repreendê-lo.

O uso que André fez do pai - não do pai simbólico, mas na construção de uma diferença instituída no real - possibilitou uma relação menos atordoante com o significante, que permitiu a nomeação, a construção de séries e a pacificação da relação com a imagem, abrindo acesso à invenção de um corpo. Através de seu ofício, algo do singular, do único e do ímpar foi atingido. Podemos dizer, então, que, a seu modo, André mordeu "un père"

\section{REFERÊNCIAS}

Freud, S. (1977). Carta 52 (J. O. A. Abreu, Trad.). Em J. Salomão (Org.), Edição standard brasileira das obras psicológicas completas de Sigmund Freud: Vol. 1 (pp. 316-324). Rio de Janeiro: Imago. (Original publicado em 1896)

Lacan, J. (1974/1975). Le seminaire, livre 22: RSI. Seminário não publicado, apresentado na Escola Freudiana de Paris.

Lacan, J. (1985). O seminário, livro 11: Os quatro conceitos fundamentais da psicanálise (M. D. Magno, Trad.). Rio de Janeiro: Jorge Zahar. (Original publicado em 1964)

Lacan, J. (1982). O seminário, livro 20: Mais, ainda (M. D. Magno, Trad.). Rio de Janeiro: Jorge Zahar. (Original publicado em 1972)

Lacan, J. (1998). Conferência em Genebra sobre o sintoma (M. Almeida, Trad.). Opção Lacaniana, 23, 6-16. (Original publicado em 1975)

Maleval, J. C. (2007). "Sobretudo verbosos", os autistas (J. M. Moura, Trad.). Latusa, 12, 69-91.

Soler, C. (2007). O inconsciente a céu aberto na psicose (V. Ribeiro Trad.). Rio de Janeiro: Jorge Zahar.

Vorcaro, A. M. R. (1997). A criança na clínica psicanalítica. Rio de Janeiro: Companhia de Freud.

Notas:

1. Esta compatibilidade não implica uma concomitância necessária. Lacan reconhece na "verbosidade" - na não extração do gozo ligado ao verbal - e não no mutismo a característica própria ao autismo (Maleval, 2007).

2. Lacan, em seu seminário Mais, Ainda, refere-se a uma dimensão da fala pensada não apenas em termos de enlace à alteridade, mas, sim, valorizando sua incidência no registro real, naquilo que o significante opera ao se explicitar "causa de gozo" (Lacan, 1982).

3. Vorcaro (1997) aborda a constituição do sujeito, segundo os seis movimentos constitutivos da trança que tece o nó borromeano. No primeiro movimento, o Real incide sobre o Simbólico traçando o recalque originário.

4. Personagens do seriado "Chaves".

5. O livro Branca de Neve e Outros Contos de Grimm fora anteriormente utilizado quase que exclusivamente no trecho em que a madrasta conversa com o espelho. Estava abandonado entre outros objetos, há anos.

6. O "quadro do amigo pretinho" foi o nome dado a um quadro pintado por Daniela, antes de ele nascer, e que precisou ser tirado da parede, devido às crises que André apresentava ao olhá-lo. Ficou guardado por muito tempo e hoje, na parede da casa de uma tia muito próxima da família, André já suporta olhá-lo, embora, eventualmente, manifeste certo mal-estar.

7. Na língua francesa, há homofonia entre "um pai” e "ímpar". 